\title{
Interviewing to Detect Deception
}

\author{
Aldert Vrij ${ }^{1}$ \\ University of Portsmouth, UK
}

\footnotetext{
${ }^{1}$ Correspondence about this article should be addressed to: Aldert Vrij, University of Portsmouth, Psychology Department, King Henry Building, King Henry 1 Street, Portsmouth, PO1 2DY, United Kingdom or via email: aldert.vrij@port.ac.uk
} 
Dear Rainer,

Anglicised

Many thanks for your and the reviewers' comments on my 'Interviewing to detect deception' article. They were helpful in improving the paper and below I explain what I have done. I noticed that you did a very good job in summarising the reviewers' comments so by addressing your seven comments I believe I have covered all the issues raised by the reviewers.

1) I have given examples of cues on pages 8,10 and 14 and as well as in other places.

2) I have added a section 'Theories about lying and cognition' and included virtually all the references the reviewer gave.

3) In addition to point 2 , I have added relevant work of others in the field, including Cognitive Interview and Reality Interview lie detection research. I have also added research on the use of drawings.

4) I have noted your fourth point, thank you for your support.

5) I have added a paragraph about using students.

6) I have added an example in the SUE section.

7) I had trouble finding redundant introduction texts and repetitions, and, in fact, only found one which I have deleted. I am happy to delete more of these if you can point out where they are?

I hope you agree with me that the paper has improved significantly and hope that the current version meets your expectations.

I look forward to hearing from you and best wishes, 
Aldert 


\begin{abstract}
DePaulo et al.'s (2003) meta-analysis of verbal and nonverbal cues to deception showed that cues to deception are faint and unreliable. If liars do not spontaneously display diagnostic cues to deceit, a logical step is to make sure that investigators elicit or enhance such cues in interviews through specific interview technique. Such interview techniques were scarce in the nonverbal and verbal cues to deception domain, but recently researchers have developed alternative protocols which have their roots in cognition and based on the assumption that questions can be asked that are more difficult for liars to answer than for truth tellers. They will be discussed in the first part of this article.

Traditionally, lie detection in a forensic context concentrated on police suspect interview settings. However, in the wake of high profile international terrorist attacks, the importance of identifying terrorist networks and gathering intelligence about the activities of such groups became paramount. Deception detection in intelligence interviews differs in several ways from deception detection in traditional police - suspect interviews and requires innovative deception research. In the second part of this article we will discuss the emerging literature in this domain.
\end{abstract}




\section{Interviewing to Detect Deception}

\section{Introduction}

In 2003 Bella DePaulo and her colleagues published their meta-analysis of verbal and nonverbal cues to deception (DePaulo et al., 2003). The meta-analysis included 50 verbal and nonverbal cues that were examined in five or more deception studies. Of these 50 cues, 14 (28\%) showed a significant relationship with deception. The average effect size of these 14 significant cues was $d=.25$. In Cohen's (1988, 1992) widely cited discussions of effect sizes he stated that $d$-values around .20 represent a small effect and argued that a small effect is a barely perceptible but real difference. He gave as an example the difference in height between 15- and 16-yearold girls (Cohen, 1988; Rice \& Harris, 2005). Given that most verbal and nonverbal cues do not appear to be related to deception at all and that those that are related only show a weak relationship with deception, the conclusion from this meta-analysis is that cues to deception are faint and unreliable.

If liars do not spontaneously display diagnostic cues to deceit, a logical step is to make sure that investigators elicit or enhance such cues in interviews through specific interview techniques (Vrij \& Granhag, 2012). Such interview techniques were scarce in the nonverbal and verbal cues to deception domain, with perhaps the Behavior Analysis Interview (Horvath, Blair, \& Buckley, 2008; Horvath, Jayne, \& Buckley, 1994; Inbau, Reid, Buckley, \& Jayne, 2013) being an exception. Such techniques are common in the physiological lie detection literature with the Comparison Question Test (CQT) being the most popular test.

The CQT is an anxiety based test and so, in part, is the BAI. The assumption in anxiety-based tests is that liars are more anxious or nervous than truth tellers and 
will therefore display physiological cues to anxiety (increased heart rate, heightened blood pressure, increased galvanic skin response) or nonverbal cues related to nervousness (gaze aversion, shifting position, increase in movements). Related to anxiety-based lie detection, the US National Research Council (NRC) published their report in 2003 in which they concluded that there is no satisfactory theoretical explanation as to why psychological states such as fear or anxiety would necessarily be stronger in liars than in truth tellers. It made some scholars realise that anxietybased interview protocols, grounded on the premise that liars are more anxious than truth tellers, are inadequate to distinguish truth tellers from liars. These scholars have argued for a change in direction (Vrij \& Granhag, 2012) and have developed alternative interview protocols which have their roots in cognition and based on the assumption that questions can be asked that are more difficult for liars to answer than for truth tellers. Three different cognitive based lie detection techniques have emerged to date: (i) imposing cognitive load, (ii) asking unanticipated questions, and (iii) using evidence in a strategic manner. They will be discussed in the first part of this article.

Traditionally, lie detection in a forensic context concentrated on police suspect interview settings. The obvious reason for this is that in criminal investigations about offences such as theft, assault, arson and murder, it is often critical to know whether the suspect is lying or telling the truth. However, in the wake of high profile international terrorist attacks, the importance of identifying terrorist networks and gathering intelligence about the activities of such groups became paramount. In addition, intelligence interviewing is often about the prevention of a crime rather than dealing with the aftermaths of a crime. Such information often comes from interviewing individuals about issues other than 'traditional crimes' and many of these interviews take place outside the police station, including at country 
borders, security checkpoints, bus terminals, train stations, shopping malls, and sports venues (Cooke \& Winner, 2008; Driskell, Salas, \& Driskell, 2012; Kimery, 2008). Again, it is often critical to determine in these interviews whether these individuals are truthful.

Deception detection in intelligence interviews differs in several ways from deception detection in traditional police - suspect interviews (Vrij \& Granhag, 2012; Vrij, Granhag, \& Porter, 2010). For example, in police - suspect interviews investigators typically focus on a suspect's past activities, but in intelligence settings investigators are often interested in someone's future activities (e.g., intentions). Another difference is that in intelligence settings investigators, and particularly those who are working in an undercover capacity, sometimes have good reason not to tell the interviewees that the 'chat' they have with them is in fact an interview. A third difference is that terrorist acts are often planned and executed by groups rather than individuals. A fourth difference is that police suspect interviews are typically focused on solving crimes through obtaining admissions or confessions from suspects, whereas intelligence interviews are more about gathering information. In the second part of this article we will discuss the emerging literature in those four areas.

The two parts of this article are clearly linked. Loftus (2011) argued that in interviewing individuals for intelligence purposes investigators need to worry about using oppressive interview techniques that could result in false confessions and false information. Anxiety-based interview techniques are oppressive in nature and run this risk, as we will show in this article. In addition, if undercover interviewers do not wish to reveal that they are actually interviewing someone, they need to have an informal chat with a person. Informal chats are by definition not oppressive in nature and, therefore, oppressive interviews are often inappropriate in intelligence 
interviewing. The cognitive lie detection techniques discussed in the first part of the article are embedded in the information-gathering interview approach, an approach that is not oppressive and encourages interviewees to talk, which is exactly the intention in intelligence interviews.

\section{Interviewing to Detect Deception: A Cognitive Approach}

\section{Theories about Lying and Cognition}

In their seminal paper about cues to deception, Zuckerman, DePaulo and Rosenthal (1981) introduced 'cognitive processing' as one of four factors that are associated with deception (the other factors were 'emotion', 'arousal' and 'control'). Cognition is also considered to be one of the main deception factors in Buller and Burgoon's (1996) Interpersonal Deception Theory, DePaulo’s Self-Presentational Perspective (DePaulo, 1992; DePaulo et al., 2003) and in Ekman's (1985/2009) work.

Several theoretical models about deception focus specifically on the role of cognition. Walczyk and colleagues introduced the Activation-Decision-Construction Model or ADCM and argued that the conscious decision to lie, inhibiting the truth, and formulating the lie are all considered to be cognitively demanding (Walczyk, Roper, Seemann, \& Humphrey, 2003; Walczyk, Schwartz, Clifton, Adams, \& Zha, 2005).

Gombos (2006) states that two executive processes play a primary role in deception which make lying cognitively more demanding: control mechanisms of thought (e.g., inhibition of the truth) and active management (tracking the reactions of the interviewer and modifying their own behaviour and speech to maintain the lie). The role of executive processes in deception also became evident in a meta-analysis of deception related fMRI research. By analysing the results of thirteen fMRI deception studies Christ and colleagues examined the role of working memory, 
inhibitory control and task switching in deception. Their analysis revealed that executive processes, and particularly working memory, play an integral role in deception (Christ, Van Essen, Watson, Brubaker, \& McDermott, 2009).

Sporer and Schwandt (2006) introduced a cognitive load/ working memory theoretical model of deception. It states that liars have to multi-task because they (i) need to plan what they are saying, attempt not to contradict themselves or the knowledge of the observer and also (ii) need to observe the listener's reactions and (iii) attempt to control their own behaviour and speech so that they can make a credible impression. Sporer and Schwandt further acknowledge that not all lies are equally difficult to formulate. For example, a prepared or rehearsed lie is easier to formulate than an unprepared or unrehearsed lie (practicing makes lying easier, see also van Bockstaele et al., 2012; Verschuere, Spruyt, Meijer, \& Otgaar, 2011); and it is easier to tell a lie in which the liar changes only a minor but important detail in an otherwise truthful story (e.g., change the date when the recalled activity took place), rather than making up an entire story. Taking this a step further, lying can sometimes even be easier than telling the truth (McCornack, 1997; Sporer \& Schwandt, 2006). Walczyk, Igou, Dixon and Tcholakian (2013) list several factors that add cognitive load to truth telling, including when memories have not been accessed for a long time, or when a truthful response requires elaboration or qualification, or the generation of a novel opinion. However, as we will argue below, investigators can elicit lengthy, spontaneous and unrehearsed answers from liars which should make lying mentally taxing.

\section{Lying Can Be More Cognitively Taxing than Truth Telling}

Lying can be more cognitively demanding than truth telling (Vrij, Fisher, Mann, \& Leal, 2006; 2008; Vrij et al., 2008). First, formulating the lie may be cognitively 
demanding. A liar needs to invent a story and must monitor their fabrication so that it is plausible and adheres to everything the observer(s) know or might find out. Moreover, liars must remember what they have said to whom in order to maintain consistency. Liars should also refrain from providing new leads (Vrij, 2008). Second, liars are typically less likely than truth tellers to take their credibility for granted (Kassin, Appleby, \& Torkildson-Perillo, 2010). As such, liars will be more inclined than truth tellers to monitor and control their demeanour in order to appear honest to the investigator, and such monitoring and controlling is cognitively demanding. Third, because liars do not take their credibility for granted, they may monitor the investigator's reactions carefully in order to assess whether they appear to be getting away with their lie (Buller \& Burgoon, 1996), which requires cognitive resources. Fourth, liars may be preoccupied with the task of reminding themselves to role-play (DePaulo et al., 2003), which requires extra cognitive effort. Fifth, deception requires a justification whereas truth telling does not (Levine, Kim, \& Hamel, 2010). People often decide to lie because they are too embarrassed to tell the truth (psychological reasons) or to gain material advantage or to avoid punishment (material reason) (DePaulo, Kashy, Kirkendol, Wyer, \& Epstein, 1996). Sixth, liars also have to suppress the truth whilst they are fabricating and this is also cognitively demanding (Spence et al., 2001). Finally, while activation of the truth often happens automatically, activation of the lie is more intentional and deliberate (Walczyk, Roper, Seemann, \& Humphrey, 2003), and thus requires mental effort.

There is substantial evidence from various sources indicating that lying is indeed more cognitively demanding than truth telling. Participants who have been asked after being interviewed about the cognitive load they experienced during the interview have reported that lying is more cognitively demanding than telling the truth. This occurred 
when the lie required lengthy, elaborative responses (e.g., Hartwig, Granhag, Strömwall, \& Kronkvist, 2006; Vrij, Mann, \& Fisher, 2006), but also when short responses were sufficient (Caso, Gnisci, Vrij, \& Mann, 2005; Vrij, Mann, \& Fisher, 2006). In fMRI deception research participants are not allowed to speak while in the scanner. Instead, they have to press a "yes" or "no" button and are requested to lie by pressing the incorrect button. Nevertheless, a review of fMRI deception research revealed that deception is associated with higher brain activity than truth telling, particularly in prefrontal regions which are associated with executive processes such as working memory, inhibitory control, and task switching (Christ, Essen, Watson, Brubaker, and McDermott, 2009). Analyses of police interviews with real-life suspects suggest that lying is also often more cognitively demanding than truth telling. First, in those police interviews lies were accompanied by increased pauses, decreased blinking, and decreased hand and finger movements, all of which are signs of cognitive load (Mann, Vrij, \& Bull, 2002; Vrij \& Mann, 2003). Second, police officers who saw a selection of these police interviews (but did not know when the suspects were lying or truth telling) reported that the suspects appeared to be thinking harder when they lied than when they told the truth (Mann \& Vrij, 2006).

\section{Imposing Cognitive Load}

An investigator could exploit the differential levels of cognitive load that truth tellers and liars experience to discriminate more effectively between them. Liars who require more cognitive resources than truth tellers will have fewer cognitive resources left over. If cognitive demand is further raised, which could be achieved by making additional requests, liars may not be as good as truth tellers in coping with these additional requests (Vrij, Granhag, Mann, \& Leal, 2011b; Vrij, Granhag, \& Porter, 2010). 
One way to impose cognitive load is by asking interviewees to tell their stories in reverse order (e.g., 'Please tell me what happened, but do this backwards and start with the last thing that you can remember happening?'). This increases cognitive load because (a) it runs counter to the natural forward-order coding of sequentially occurring events and (b) it disrupts reconstructing events from a schema (Gilbert \& Fisher, 2006). In one experiment, half of the liars and truth tellers were requested to recall their stories in reverse order (Vrij et al., 2008), whereas no instruction was given to the other half of participants. More cues to deceit emerged in the reverse order (such as lack of spatial details, auditory details, contextual embeddings) than in the control conditions (decrease in hand/finger movement only). Observers who watched these videotaped interviews could distinguish between truths and lies better in the reverse order condition than in the control conditions. For example, in the reverse order experiment, $42 \%$ of the lies were correctly classified in the control condition, well below that typically found in verbal and nonverbal lie detection research, suggesting that the lie detection task was difficult. Yet, in the experimental condition $60 \%$ of the lies were correctly classified, which is more than typically found in this type of lie detection research (Bond \& DePaulo, 2006).

The reverse order technique is one of the components of the Cognitive Interview (Fisher \& Geiselman, 1992). The Cognitive Interview is a sophisticated interview technique based on memory theory, social dynamics and communication. The Cognitive Interview results in truthful examinees providing a more detailed and accurate recall of an experienced event (Fisher, 2010), and has been shown to elicit considerably more information than typical police or other recommended interview protocols (see Memon, Meissner, \& Fraser, 2010, for a meta-analysis.) Experimental deception studies in which the Cognitive Interview was compared with a 'standard' 
interview revealed that 'detail' occurred as a cue to deceit more frequently in the Cognitive Interview than in the standard interview and that the Cognitive Interview facilitated lie detection (Colwell, Hiscock, \& Memon, 2002; Hernandez-Fernaud \& Alonso-Quecuty, 1997; Zimmerman, Veinott, Meissner, Fallon, \& Mueller, 2010, but see Bembibre \& Higueras (2011, 2012, for exceptions). See also research into the Reality Interview, a permutation of the original Cognitive Interview (Ansarra et al., 2011; Colwell, Hiscock-Anisman, Memon, Taylor, \& Prewett, 2007; Suckle-Nelson et al., 2010).

Another type of additional request that could be introduced is asking interviewees to carry out a secondary task at the same time as recalling their stories. Carrying out two tasks simultaneously (storytelling and a secondary task unrelated to storytelling) is cognitively more difficult than carrying out one task (i.e., just storytelling), because in the former situation interviewees need to divide their attention between the two tasks (Johnston, Greenberg, Fisher, \& Martin, 1970; Smith, 1969). For example, interviewees could be asked to recall their stories while conducting a computer driving simulation task or driving a real car. Liars may find this dual task more cognitively difficult than truth tellers and may not cope as well with this request. More pronounced differences between truth tellers and liars in story telling may thus occur in the driving condition compared to the control condition. Two studies to date have found support for this assumption, and both measured reaction times. Debey, Verschuere and Crombez (2012) introduced a hand grip task whereby participants were required to squeeze a spring-loaded handgrip for as long as possible. Squeezing a handgrip is a measure of muscular strength and self-control, becomes tiring after a short period of time, and participants must pay attention to this task by exerting self-control to override the urge to quit. Liars' reaction times in a deception 
test were more affected by these lapses of attention than truth tellers' reaction times. In Visu-Petra, Varga, Miclea, and Visu-Petra's (2013) experiment, truth tellers' and liars' reaction times were measured in a recognition test under standard conditions or under conditions in which additional tasks were introduced (e.g., pressing a key once or twice depending on whether the answers were written in bold or italics). Liars' reaction times were longer than those of truth tellers, particularly in the conditions that contained interfering tasks.

\section{Asking Unanticipated Questions}

A consistent finding in deception literature is that liars prepare themselves for possible interviews by thinking of answers to questions they expect to be asked (Hartwig, Granhag, \& Strömwall, 2007). The strategy of preparing answers to possible questions makes sense. Planning makes lying easier, and planned lies typically contain fewer cues to deceit than do spontaneous lies (DePaulo et al., 2003). However, the positive effects of planning will only emerge if liars correctly anticipate which questions will be asked. Investigators can exploit this limitation by asking questions that liars do not anticipate. Though liars can refuse to answer unanticipated questions, such "I don't know" or "I can't remember" responses will create suspicion and should therefore be avoided if the questions are about central aspects of the target event. A liar, therefore, has little option other than to fabricate a plausible answer on the spot, which is cognitively demanding. For liars, expected questions should be easier to answer than unexpected questions, because liars can give their planned and rehearsed answers to the expected questions but they need to fabricate an answer to the unexpected questions. The difference liars experience in cognitive load while answering these two sets of questions should become evident in their verbal responses. In contrast, truth tellers experience similar levels of cognitive load while answering expected and unexpected questions, and 
they should produce more comparable answers to the expected and unexpected questions than liars. In Lancaster, Vrij, Hope, and Waller (2012) truth tellers and liars were interviewed about their alleged activities in a room. Expected questions (e.g., 'Tell me in as much detail as you can what you did in the room') were followed by unexpected spatial and temporal questions (e.g., 'Please describe exactly how you arranged the four objects you placed on the table at the centre of the room'). Liars gave significantly more detail to the expected questions than truth tellers and significantly less detail to the unexpected questions than truth tellers. As a result, the difference in detail between the expected and unexpected questions was larger in liars than in truth tellers and based on this difference score $78 \%$ of truth tellers and $83 \%$ of liars were correctly classified.

The unexpected questions approach is also effective when interviewing pairs of suspects individually. In all likelihood pairs of guilty suspects have prepared possible answers to questions that will likely be asked. If these questions are indeed asked in the separate interviews, they will be able to give similar answers. If unexpected questions are asked, their answers are likely to differ from each other. In Vrij et al. (2009) pairs of liars and pairs of truth tellers were interviewed individually about having had lunch together at a restaurant. Although the pairs of truth tellers did not have lunch together, the liars were instructed to pretend that they had. All pairs were given the opportunity to prepare for the interview. Typical opening questions were asked that the interviewees later said they had expected (e.g., "What did you do in the restaurant?"), followed by spatial questions (e.g., "In relation to the front door, where did you and your friend sit?"), temporal details (e.g., "Who finished their food first, you or your friend?"), and a request to draw the layout of the restaurant, which were all unexpected questions according to the interviewees. The pairs of liars showed the same amount of overlap in their responses to the expected opening 
questions as the pairs of truth tellers, but less overlap than truth tellers in their responses to the unexpected questions. Based on overlap in answer to the spatial questions, $72 \%$ of pairs of truth tellers and liars could be classified (i.e., the answers were less alike for the pairs of liars than they were for the truth tellers). This demonstrates the potential of asking spatial questions for lie detection purposes. An even higher percentage of truth telling and lying pairs, $78 \%$, could be correctly classified when assessing their drawings (i.e., the drawings were less alike for the pairs of liars than they were for the truth tellers). In summary, when liars have anticipated the questions their answers made them undistinguishable from truth tellers. Only asking unexpected questions about central topics led to identifiable betrayals for liars.

Vrij et al. (2009), discussed in the previous paragraph, were the first researchers to use drawings as a lie detection tool, and since then more work has been carried out in this area (Leins, Fisher, \& Vrij, 2012; Leins, Fisher, Vrij, Leal, \& Mann, 2011; Roos af Hjelmsäter, Öhman, Granhag, \& Vrij, in press; Vrij, Leal, Mann, Warmelink, Granhag, \& Fisher, 2010; Vrij, Mann, Leal, \& Fisher, 2012). Roos af Hjelmsäter and her colleagues found that for the unanticipated-questions technique to work only questions about core events should be asked (Roos af Hjelmsäter, Ohman, Granhag, \& Vrij, in press). Adolescents (13-14 years-old) experienced in groups of three an encounter with a man near a statue (truth tellers) or they imagined this event (liars). In the subsequent interview, in which the adolescents were interviewed individually, they were asked to give a general verbal description of the event (anticipated task) or to produce spatial information by sketching (unanticipated task) from which direction the man had come (core event) or where each of the three group members had stood when talking to the man (peripheral event). The liars' and 
truth tellers' verbal responses showed similar overlap, and so did their drawings about the peripheral elements of the task. However, liars' drawings showed less overlap than the truth tellers' drawings about the core event.

Leins and colleagues $(2011,2012)$ explored the use of drawings in eliciting inconsistencies in liars' responses. They asked their participants the same question twice albeit in different formats (verbal recall versus sketching). They found that liars showed more inconsistencies between verbal recall and drawing than truth tellers, which can be explained by the fact that truth tellers will have encoded the topic of investigation along more dimensions than liars. As a result, compared with liars, truth tellers should be able to recall the event more flexibly (along more dimensions). For this method to work it is crucial that the same question is asked in different dimensions (e.g., verbal recall versus sketching). Leins et al. (2012) found that when truth tellers and liars were asked to verbally recall the event twice or asked to sketch the event twice no differences emerged between truth tellers and liars.

Vrij and colleagues $(2010,2012)$ compared the detail of verbal recalls and drawings when participants were asked to describe/sketch the layout of a location and other people. They found that truth tellers were more detailed when sketching a layout or people, the result of at least two factors. First, the request to sketch the layout of a location implies that an interviewee has to convey specific spatial information (e.g., a bin needs to be positioned in an exact location in the room, for example at the left hand side of the table), whereas such exact locations of an object are not a necessary requirement for a verbal description ('e.g., there was a table with a bin next to it...'). Therefore when truthful interviewees verbally describe a room and the objects within, they may be less specific about the location of the objects or may not mention their location at all. In terms of sketching/describing who else was in the room, 
idiosyncratic features of people (e.g., wearing glasses, having curly hair) were more often present in the truth tellers' sketches than in their verbal recalls. In other words, the request to sketch people encouraged truth tellers to convey detailed information that they did not convey when asked to verbally describe these people. Since the truth tellers' drawings were particularly detailed, differences between them and liars were most likely to occur in the drawing condition. Second, for truth tellers to judge whether they have conveyed all the information they know, they need to have an accurate understanding of the information they have conveyed. In a case where they have sketched the layout or people, that information is visible in the drawing. In a case where they have verbally recalled the layout or people, that information is not visible and the interviewee needs to build a mental picture of what $\mathrm{s} / \mathrm{he}$ has said. Judging a drawing for omissions or completeness is easier than judging a mental picture for omissions or completeness, and omissions are therefore more easily noticed in drawings than in verbal recalls.

\section{The Strategic Use of Evidence}

Liars (guilty suspects) and truth tellers (innocent suspects) generally enter interviews with different counter-interrogation strategies (Granhag \& Hartwig, 2008). Research suggests that liars are inclined to use avoidance strategies (e.g., avoiding mentioning where they were at a certain time) or denial strategies (e.g., denying having been at a certain place at a certain time when asked directly). In contrast, truth tellers are generally more forthcoming and "tell the truth like it happened" (Hartwig, Granhag \& Strömwall, 2007).

When investigators possess critical and possibly incriminating background information (evidence), they can exploit these differential truth tellers' and liars' strategies by introducing the available evidence during the interview in a strategic 
manner (the Strategic Use of Evidence technique, SUE). When questions are asked about the evidence, guilty suspects tend to use more avoidance strategies, whereas innocent suspects use more forthcoming strategies (Granhag \& Hartwig, 2008); hence, innocent suspects' accounts will be more consistent with the available evidence than guilty suspects' accounts.

Granhag, Strömwall, Willén, and Hartwig (2013) introduced the so-called Evidence Framing Matrix which suggests that when one piece of evidence is disclosed, two dimensions are particularly helpful in illuminating the different framing alternatives that exist. The first dimension is the strength of the source of the evidence, which can vary from weak ('We have information that...') to strong ('CCTV footage shows that...'). The second dimension is the degree of precision of the evidence, which can vary from low ('...you entered the train station') to high ( '...you collected a package from a deposit box at the central station, ground floor level, on the $24^{\text {th }}$ of August at 7.30pm'). Granhag et al.'s (2013) found that using this matrix to reveal the evidence in a stepwise manner moving from the most indirect form of framing (weak source/low specificity, e.g., 'We have information telling us that you recently visited the central station') to the most direct form of framing (strong source/high specificity, e.g., 'We have CCTV footage showing that you collected a package from a deposit box at the central station, ground floor level, on the $24^{\text {th }}$ of August at $7.30 \mathrm{pm}$ ') elicited more and stronger cues to deception than using the most direct form of framing only. When confronted with the direct form of framing at the first instance, liars may admit to collecting the package and may try to give an innocent explanation. Based on the notion that liars will use aversive strategies, it is unlikely that they will admit to collecting the package after being exposed to the most indirect form of framing. However, they are likely to change their 
story when new evidence is presented so that their story continues to match the evidence. Such a response pattern results in within-statement inconsistencies.

Police trainees were taught to use some basic elements of the SUE-technique. Results showed that participants who received training clearly outperformed their untrained colleagues: $85 \%$ vs. $56 \%$ deception detection performance (Hartwig, Granhag, Strömwall and Kronkvist 2006). The SUE-technique has been found to be successful in eliciting cues to deception (inconsistencies between statement and evidence) for adults and children, for single suspects and multiple suspects, and for suspects lying about their past actions and about their intentions (Vrij \& Granhag, 2012).

\section{Lie Detection in Intelligence Settings}

Police - suspect interviews differ in certain important aspects from intelligence interviews. To gain understanding into deception and lie detection in intelligence settings, key aspects of intelligence settings need to be introduced and simulated in deception research. Researchers have only recently started to do this. This section outlines some of the key aspects of intelligence interviewing together with the first research output available in this domain.

\section{Lying about Intentions}

Most forensic deception research deals with lying about past activities. This makes sense because most of that research focuses on police interviewing and the police mostly interview suspects about their alleged past activities. However, in intelligence settings, being able to discriminate between true and false accounts about future activities (e.g., intentions) is of paramount importance, as this addresses the issue of preventing criminal acts from occurring, including terrorist attacks. Most of the lying about intentions research has been carried out by Pär Anders Granhag and 
his colleagues, and that research is discussed elsewhere in this special issue (Granhag, in press). In this section, one experiment will be discussed with possibly significant implications (Warmelink, Vrij, Mann, Jundi, \& Granhag, in press). In the experiment truth tellers and liars were interviewed about their alleged forthcoming trip. Anticipated questions about the purpose of the trip (e.g., "What is the main purpose of your trip?"), were followed by unanticipated questions about transport (e.g., "How are you going to travel to your destination?"), planning (“What part of the trip was easiest to plan?"), and the core event ("Keep in mind an image of the most important thing you are going to do on this trip. Please describe this mental image in detail?”). A pilot study indicated that these questions were genuinely unanticipated, and liars gave significantly more detail to the anticipated questions and significantly less detail to the unanticipated questions than truth tellers.

This experiment has real life implications. Throughout the world immigration officers mainly ask purpose questions when quizzing passengers at airport border controls. In all likelihood they pay attention to the amount of detail passengers give, with the notion being that the richer an account is perceived to be in detail, the more likely it is to be believed (e.g., Bell \& Loftus, 1989). However, purpose questions are expected by potential wrongdoers, for example, they appear in the al-Qaeda 'Manchester Manual', a manual for potential terrorists with information on how to avoid detection. Because purpose questions are expected, potential wrongdoers are able to answer such questions in detail and will subsequently make an honest impression on immigration officers.

\section{Interviewing without Being Noticed (Undercover Interviewing)}

In intelligence settings it may be useful to conduct interviews without the suspect actually knowing they are being interviewed. This is called undercover interviewing 
(Vrij, Mann, Jundi, Hope, \& Leal, 2012). Undercover interviewing may fit particularly well in terms of determining the veracity of an individual's intentions. At the intentions stage, no crime has yet been committed, and a formal interview may therefore be inappropriate. In addition, in some investigative contexts, law enforcement and security personnel may have good reason to extract information from a suspect without them actually being aware that they are under investigation. In particular, law enforcement officers working as undercover agents and interacting with potential suspects in informal settings will not wish to draw attention to themselves or arouse suspicion about their motives by using direct question formats. For example, when an undercover officer has become embedded within a criminal gang or is required to interact with suspects to collect intelligence, the ability to elicit relevant information without detection is critical.

The necessity to maintain undercover determines the questions that can be asked, and has several disadvantages and advantages in terms of lie detection. Starting with the disadvantages, interview tools that have shown to facilitate lie detection discussed in this article, such as asking a person to recall a story in reverse order, cannot be employed without making the suspect suspicious about the questioner's motives. In terms of advantages, undercover interviewing creates the opportunity to ask questions that could be useful for lie detection purposes but which would not work in traditional overt interviews. For example, the undercover interviewer could invite suspects to engage in an apparently innocent activity that establishes their presence in a certain place at a certain time, such as asking whether the suspect would mind having a photograph taken that the interviewer could place on a website. Given that a plausible rationale for this request is provided (e.g. 'I've just started a new business and I'm trying to build up my reputation as a photographer") truth tellers and liars may well respond differently to this 
seemingly innocuous compliance request. Research has shown that guilty people do not wish to be linked to their criminal activity and tend to 'avoid and escape' when asked about it (Granhag \& Hartwig, 2008), and may therefore show greater reluctance to be photographed.

Vrij, Mann, Jundi et al. et al. (2012) carried out the first undercover interviewing deception experiment ever published. In that experiment the participants were interviewed by a mock 'undercover agent', acting either as a doctoral student or as an amateur photographer. He approached either tourists (truth tellers) or participants who were on a mock reconnaissance mission (liars) at a hovercraft terminal, and asked them questions about their forthcoming trip to a nearby island. The liars had been instructed to prepare as a cover-story that they were going to visit the island as a tourist, and were given a tourist flyer about the island to prepare their cover story. The undercover interviewer asked the participants why they were visiting the island, at what time they were planning to come back, and to indicate on a blind map of the island the locations they planned to visit. He also asked their permission to take their photograph. Research has revealed that an individual who is about to execute his/her intention typically has a detailed mental representation of that intention (Trope \& Liberman, 2003). This representation is more detailed than those of intentions the individual plans to execute at some later time (Trope \& Liberman, 2003). It also differs from the mental representations of intentions that the person has not yet decided to execute (Ferguson \& Bargh, 2004; Marsh, Hicks, \& Bryan, 1999). Based on this, truth tellers may be more precise when describing their intentions (e.g., more references to exact timings) and may express more certainty in what they are going to do than liars. People typically do not anticipate, and are thus unprepared for, spatial questions (Vrij et al., 2009). Therefore, such questions in particular should reveal deceit. In terms of visiting an island, it could 
be that liars identify which attractions they are supposedly going to visit but do not check specifically where they are located. As a result, liars may be less accurate than truth tellers in reporting exact locations of their alleged destinations on the island. In alignment with these predictions, truth tellers, compared to liars, gave more detailed answers, were more exact about the time at which they planned to return from the island, were more precise in indicating the exact locations of the places they were going to visit and were more willing to be photographed. When participants were asked after their encounter with the undercover agent about their experiences during the interview, they mentioned that they found only the request to have their photograph taken somewhat odd. In sum, this experiment revealed that undercover interviewing can be used effectively to detect deceit.

In Vrij, Mann, Jundi et al. et al.’s (2012) experiment, as in most deception studies, the liars were university students and staff working at the university. Of course, this raises the question of whether similar results would be found with real terrorists. This is an empirical question worth examining, but we are hopeful that this will be the case. For example, this experiment, as well as another deception experiments discussed earlier (Vrij et al., 2009) indicated that spatial questions are good for lie detection. Ali Soufan, an FBI interrogator, noticed exactly the same when interrogating terrorists (Soufan, 2011).

\section{Lying in Groups (Collective Interviewing)}

Terrorist acts are often planned and executed by groups rather than individuals (Crenshaw, 1990; Soufan, 2011). For example, the terrorists travelled together to London to carry out the London 2005 bombings. Therefore, investigators may wish to interview people at specific locations, such as in a shopping mall, at the entrance of a football stadium, at the entrance of the underground, or at a road border control. This 
may then result in situations in which there is only one interviewer available but a group of suspects.

Interviewing suspects collectively enables investigators to examine how group members communicate with each other when lying or truth telling. When pairs of truth tellers recall a jointly experienced event during an interview, they may communicate substantially with each other in an attempt to collectively recall all the details they know, and to correct each other's stories. In this respect, Hollingshead (1998) refers to transaction information search, the idea that people in interpersonal relationships often have a specialised 'division of labour' with respect to encoding, storing, and retrieving information from different domains (Wegner, 1987). Truth tellers, having shared experience of an actual event, may naturally make use of this transactive memory by cuing one another, posing questions to one another, and verbalising connections asking each other questions that could tap into the other's memory domain. In contrast, liars do not have a joint experience to recall. They may provide their prepared answers to anticipated questions, or if the questions were not anticipated, one person may take the lead and the other may simply agree with what is said. This is a far less interactive approach than the truth tellers' approach, and, indeed, in two collective interviewing experiments to date, the pairs of liars made fewer additions, corrections and interruptions than the pairs of truth tellers ((Driskell, Salas, \& Driskell, 2012; Vrij et al., 2012). Of course, interacting with each other is associated with mutual gaze. Two experiments revealed that truthful dyads gazed more at their partner than deceptive dyads (Driskell et al., 2012; Jundi et al., 2012). Jundi et al. (2012) also found that pairs of liars looked more at the interviewer than pairs of truth tellers. In sum, collective interviewing has shown promise in terms of lie detection because truthful and deceptive dyads communicate differently with each 
other.

\section{Information-Gathering versus Accusatory Interviewing}

Whereas police interviews are sometimes aimed at obtaining confessions, intelligence interviews are mostly about gathering information (Borum, 2006; Brandon, 2011). A necessary condition for gathering information is that interviewees talk. Information-gathering interview protocols encourage interviewees to talk (Bull, 2010; Fisher, 2010; Lamb, Hershkowitz, Orbach, \& Esplin, 2008). They are amongst other aspects characterised by providing opportunities for uninterrupted recall (Meissner, 2011). The stereotypical view, often addressed in police manuals (e.g., Inbau et al., 2013) is that interviewees are reluctant to talk and that investigators need to use an accusatory approach to get them to talk, characterised by confrontation, and the use of minimisation and maximisation techniques (Meissner, 2011; Soufan, 2011). The view that an accusatory approach is required to get people to talk is by no means shared by all practitioners. For example, Soufan (2011), an experienced and successful American FBI interrogator who gathered valuable information from alQaeda suspects, did not use an accusatory approach when interviewing them. Instead he used an information-gathering approach characterised by rapport building, truth seeking and listening. In addition, the Canadian police detective Tedeschini (2012) also advocates the information-gathering approach.

Research has shown that the idea that suspects in police interviews are unwilling to talk in information-gathering style interviews is a myth rather than fact. A systematic analysis of more than 1,067 information-gathering police interviews in the UK has shown that only $5 \%$ of the suspects remained silent (Moston, Stephenson, \& Williamson, 1993). In addition, in his analysis of 600 information-gathering police interviews, Baldwin (1993) found that $80 \%$ of the suspects were thoroughly 
cooperative and answered police questions of significance. Furthermore, a recent meta-analysis of field and laboratory studies about the influence of the interview/interrogation method on eliciting information, cues to deceit and confession outcomes revealed that information-gathering approaches elicited significantly more relevant information and significantly more diagnostic cues to deceit than accusatorial methods (Meissner, 2011; Meissner, Redlich, Bhatt, \& Brandon, 2012). In addition, information-gathering approaches significantly increased the likelihood of true confessions and significantly decreased the likelihood of false confessions compared to accusatory approaches, and accusatory approaches significantly increased both true and false confessions compared to control conditions. In summary, research findings do not support the idea that suspects are reluctant to talk and that accusatory techniques are needed to yield success in interviews. On the contrary, an informationgathering approach yields better results than an accusatory approach in obtaining relevant information, eliciting cues to deceit and obtaining confessions.

\section{Conclusion}

This article has introduced cognitive lie detection. Three interview techniques were described; imposing cognitive load, asking unanticipated questions, and the strategic use of evidence that have in common that liars find them more difficult to cope with than truth tellers. This results in cues to deceit (deceptive statements lack detail and contain inconsistencies) and better discrimination between truth tellers and liars. All three interview techniques use an information-gathering interview style and they can be employed in a variety of settings, including in intelligence interviewing where the traditional oppressive accusatory interview style is often inappropriate. 


\section{References}

Ansarra, R., Colwell, K., Hiscock-Anisman, C., Hines, A., Fleck, R., Cole, L., \& Belarde, D. (2011). Augmenting ACID with affective details to assess credibility. The European Journal of Psychology Applied to Legal Context, 3, 141-158.

Baldwin, J. (1993). Police interview techniques. British Journal of Criminology, 33, 325-352.

Bell, B. E., \& Loftus, E. F. (1989). Trivial persuasion in the courtroom: The power of (a few) minor details. Journal of Personality and Social Psychology, 56, 669-679.

Bembibre, J., \& Higueras, L. (2011). Differential effectiveness of the cognitive interview in a simulation of a testimony. Psychology, Crime, \& Law, 17, 473-489. DOI $10.1080 / 10683160903321540$

Bembibre, J., \& Higueras, L. (2012). Comparative analysis of true and false statements with the source monitoring model and the cognitive interview: Special features of the false accusation of innocent people. Psychology, Crime, \& Law, 18, 913-928. DOI 10.1080/1068316X.2011.589387

Bond, C. F., \& DePaulo, B. M. (2006). Accuracy of deception judgements. Personality and Social Psychology Review, 10, 214-234.

Borum, R. (2006). Approaching truth: Behavioral science lessons on educing information from human sources. In Intelligence Science Board. Educing information. Interrogation: Science and Art (pp. 17-43). Washington, DC: National Defense Intelligence College.

Brandon, S. (2011). Impacts of psychological science on national security agencies post-9/11. American Psychologist, 66, 495-506.

Bull, R. (2010). The investigative interviewing of children and other vulnerable witnesses: Psychological research and working/professional practice. Legal and Criminological Psychology, 15, 5-24. 
Buller, D. B., \& Burgoon, J. K. (1996). Interpersonal deception theory. Communication Theory, 6, 203-242.

Caso, L., Gnisci, A., Vrij, A., \& Mann, S. (2005). Processes underlying deception: An empirical analysis of truths and lies when manipulating the stakes. Journal of Interviewing and Offender Profiling, 2, 195-202.

Christ, S., E., Van Essen, D. C. Watson, J. M., Brubaker, L. E., \& McDermott, K. B. (2009). The Contributions of Prefrontal Cortex and Executive Control to Deception: Evidence from Activation Likelihood Estimate Meta-analyses. Cerebral Cortex, 19, 1557-1566.

Cohen, J. (1988). Statistical power analysis for the behavioral sciences (2nd ed.). Hillsdale, NJ: Erlbaum.

Cohen, P. (1992). A power primer. Psychological Bulletin, 122, 155-159.

Colwell, K., Hiscock, C. K., \& Memon, A. (2002). Interview techniques and the assessment of statement credibility. Applied Cognitive Psychology, 16, 287-300.

Colwell, K., Hiscock-Anisman, C., Memon, A., Rachel, A, \& Colwell, L. (2007). Vividness and spontaneity of statement detail characteristics as predictors of witness credibility. American Journal of Forensic Psychology, 25, 1-26.

Cooke, N. J., \& Winner, J. L. (2008). Human factors of homeland security. In D. A. BoehmDavis (Ed.), Reviews of human factors and ergonomics, volume 3 (pp. 79-110). Santa Monica, CA: Human Factors and Ergonomics Society.

Crenshaw, M. (1990). Questions to be answered, research to be done, knowledge to be applied. In W. Reich (Ed.), Origins of terrorism: Psychologies, Ideologies, theologies, states of mind (pp. 247-260). Cambridge, England: Cambridge University Press.

Debey, E., Verschuere, B., \& Crombez, G. (2012). Lying and executive control: An experimental investigation using ego depletion and goal neglect. Acta Psychologica, $140,133-141$. 
DePaulo, B. M. (1992). Nonverbal behavior and self-presentation. Psychological Bulletin, 111, 203-243.

DePaulo, B. M., Kashy, D. A., Kirkendol, S. E., Wyer, M. M., \& Epstein, J. A. (1996). Lying in everyday life. Journal of Personality and Social Psychology, 70, 979-995.

DePaulo, B. M., Lindsay, J. L., Malone, B. E., Muhlenbruck, L., Charlton, K., \& Cooper, H. (2003). Cues to deception. Psychological Bulletin, 129, 74-118.

Driskell, J. E., Salas, E., \& Driskell, T. (2012). Social indicators of deception. Human Factors: The Journal of the Human Factors and Ergonomics Society, 54, 4577-4588.

Ekman, P. (1985). Telling lies: Clues to deceit in the marketplace, politics and marriage. New York: W. W. Norton. (Reprinted in 1992, 2001 and 2009).

Ferguson, M. J., \& Bargh, J. A. (2004). Liking is doing: The effects of goal pursuit on automatic evaluation. Journal of Personality and Social Psychology, 87, 557-572.

Fisher, R. P. (2010). Interviewing cooperative witnesses. Legal and Criminological Psychology, $15,25-38$

Fisher, R., P. \& Geiselman, R. E. (1992). Memory-enhancing techniques in investigative interviewing: The cognitive interview. Springfield, IL: C.C. Thomas.

Gilbert, J. A. E., \& Fisher, R. P. (2006). The effects of varied retrieval cues on reminiscence in eyewitness memory. Applied Cognitive Psychology, 20, 723-739.

Gombos, V. A. (2006). The cognition of deception: The role of executive processes in producing lies. Genetic, Social, and General Psychology Monograhs, 132, 197-214.

Granhag, P.A. \& Hartwig, M. (2008). A new theoretical perspective on deception detection: On the psychology of instrumental mind-reading. Psychology, Crime \& Law, 14, 189-200.

Granhag, P.A., Strömwall, L.A., Willén, R., \& Hartwig, M. (2013). Eliciting cues to deception by tactical disclosure of evidence: The first test of the Evidence Framing Matrix. Legal and Criminological Psychology, 18, 341-355. DOI. 10.1111/j.2044- 
8333.2012.02047.x

Hartwig, M., Granhag, P. A., \& Strömwall, L. (2007). Guilty and innocent suspects' strategies during interrogations. Psychology, Crime, \& Law, 13, 213-227.

Hartwig, M., Granhag, P. A., Strömwall, L., \& Kronkvist, O. (2006). Strategic use of evidence during police interrogations: When training to detect deception works. Law and Human Behavior, 30, 603-619.

Hernandez-Fernaud, E., \& Alonso-Quecuty, M. (1997). The cognitive interview and lie detection: A new magnifying glass for Sherlock Holmes? Applied Cognitive Psychology, $11,55-68$.

Hollingshead, A. B. (1998). Retrieval processes in transactive memory systems. Journal of Personality and Social Psychology, 74, 659-671.

Horvath, F., Blair, J. P., \& Buckley, J. P. (2008). The Behavioral Analysis Interview: Clarifying the practice, theory and understanding of its use and effectiveness. International Journal of Police Science and Management, 10, 101-118.

Horvath, F., Jayne, B., \& Buckley, J. (1994). Differentiation of truthful and deceptive criminal suspects in behavioral analysis interviews. Journal of Forensic Sciences, 39, 793-807.

Inbau, F. E., Reid, J. E., Buckley, J. P., \& Jayne, B. C. (2013). Criminal interrogation and confessions, $5^{\text {th }}$ edition. Burlington, MA: Jones \& Bartlett Learning.

Johnston, W. A., Greenberg, S. N., Fisher, R. P., \& Martin, D. W. (1970). Divided attention: A vehicle for monitoring memory processes. Journal of Experimental Psychology, 83, 164-171.

Jundi, S., Vrij, A., Mann, S., Hope, L., Hillman, J., Warmelink, L., \& Gahr, E. (in press). Who should I look at? Eye contact during collective interviewing as a cue to deceit. Psychology, Crime, \& Law. 
Kassin, S. M., Appleby, S. C., \& Torkildson-Perillo, J. (2010). Interviewing suspects: Practice, science, and future directions. Legal and Criminological Psychology (Special issue "What works in investigative psychology"), 15, 39-56.

Kimery, A. L. (2008, April 29). Airport security: Keep your shoes on and tell the truth. Homeland Security Today. Retrieved from http://www.hstoday.us/index.php?id=483\&cHash=081010\&tx_ttnews[tt_news]=3219

Lamb, M. E., Hershkowitz, I., Orbach, Y., \& Esplin, P. W. (2008). Tell me what happened: Structured investigative interviews of child victims and witnesses. Chichester, UK and Hoboken, NJ: Wiley.

Lancaster, G. L. J., Vrij, A., Hope, L., \& Waller, B. (2012). Sorting the liars from the truth tellers: The benefits of asking unanticipated questions. Applied Cognitive Psycholog, $27,107-114$.

Leins, D., Fisher, R., \& Vrij, A. (2012). Drawing on liars' lack of cognitive flexibility: Detecting deception through varying report modes. Applied Cognitive Psychology, 26, 601-607. DOI 10.1002/acp.2837

Leins, D., Fisher, R. P., Vrij, A., Leal, S., \& Mann, S. (2011). Using sketch-drawing to induce inconsistency in liars. Legal and Criminological Psychology, 16, 253-265. DOI 10.1348/135532510X501775

Levine, T. R., Kim, R. K., \& Hamel, L. M. (2010). People lie for a reason: Three experiments documenting the principle of veracity. Communication Research Reports, 27, 271-285.

Loftus, E. F. (2011). Intelligence gathering post-9/11. American Psychologist, 66, 532-541.

Mann, S. \& Vrij, A. (2006). Police officers' judgements of veracity, tenseness, cognitive load and attempted behavioural control in real life police interviews. Psychology, Crime, \& Law, 12, 307-319. 
Mann, S., Vrij, A., \& Bull, R. (2002). Suspects, lies and videotape: An analysis of authentic high-stakes liars. Law and Human Behavior, 26, 365-376.

Marsh, R. L., Hicks, J. L., \& Bryan, E. S. (1999). The activation of unrelated and cancelled intentions. Memory \& Cognition, 27, 320-327.

McCornack, S. A. (1997). The generation of deceptive messages: Laying the groundwork for a viable theory of interpersonal deception. In J. O. Greene (Ed.), Message production: Advances in communication theory (pp. 91-126). Mahway, NJ: Lawrence Erlbaum.

Meissner, C. A. (2011). Evidence-based approaches to forensic interviewing and credibility assessment. Paper presented at the Federal Law Enforcement Training Center, Brunswick, Georgia, US, August 11.

Meissner, C. A., Redlich, A. D., Bhatt, S., \& Brandon, S. (2012). Interview and interrogation methods and their effects on true and false confessions. Campbell Systematic Reviews 2012:13. DOI: 10.4073/csr.2012.13.

Memon, A., Meissner, C, A., \& Fraser, J. (2010). The cognitive interview: A meta-analytic review and study space analysis of the past 25 years. Psychology, Public Policy, \& Law, 16, 340-372.

Moston, S. J., Stephenson, G. M., \& Williamson, T. M. (1993). The incidence, antecedents and consequences of the use of the right to silence during police questioning. Criminal Behaviour and Mental Health, 3, 30-47.

National Research Council (2003). The polygraph and lie detection. Committee to Review the Scientific Evidence on the Polygraph. Washington, DC: The National Academic Press.

Rice, M., \& Harris, G. T. (2005). Comparing Effect Sizes in Follow-Up Studies: ROC Area, Cohen's $d$, and r. Law \& Human Behavior, 29, 5, 615 - 620.

Roos af Hjelmsäter, E., Öhman, L., Granhag, P. A., \& Vrij, A. (in press). Mapping’ deception 
in adolescents: Eliciting cues to deceit through an unanticipated spatial drawing task. Legal and Criminological Psychology.

Smith, M. C. (1969). Effect of varying channel capacity on stimulus detection and discrimination. Journal of Experimental Psychology, 82, 520-526.

Soufan, A. H. (2011). The black banners: The inside story of $9 / 11$ and the war against alQaeda. New York: W. W. Norton \& Company.

Spence, S. A., Farrow, T. F. D., Herford, A. E., Wilkinson, I. D., Zheng, Y., \& Woodruff, P. W. R. (2001). Behavioural and functional anatomical correlates of deception in humans. Neuroreport: For Rapid Communication of Neuroscience Research, 12, 2849-2853.

Sporer, S. L., \& Schwandt, B. (2006). Paraverbal indicators of deception: A meta-analytic synthesis. Applied Cognitive Psychology, 20, 421-446.

Suckle-Nelson, J. A., Colwell, K., Hiscock-Anisman, C., Florence, S., Youschak, K. E., \& Duarte, A. (2010). Assessment criteria indicative of deception (ACID): Replication and gender differences. The Open Criminology Journal, 3, 23-30.

Tedeschini, J. (2012). Overcoming roadblocks to reform. Journal of Applied Research in Memory and Cognition, 1, 134-135.

Trope, Y., \& Liberman, N. (2003). Temporal construction. Psychological Review, 110, 403-421.

Van Bockstaele, B., Verschuere, B., Moens, T., Suchotzki, K., Debey, E., \& Spruyt, A. (2012). Learning to lie: Effects of practice on the cognitive costs of lying. Frontiers in Psychology, 3, 526.

Verschuere, B., Spruyt, A., Meijer, E. H., \& Otgaar, H. (2011). The ease of lying. Consciousness and Cognition, 20, 908-911.

Visu-Petra, G., Varga, M., Miclea, M., \& Visu-Petra, L. (2013). When interference helps: increasing executive load to facilitate deception detection in the concealed information test. Frontiers in Psychology, 4, 146. DOI 10.3389/fpsyg.2013.00146. 
Vrij, A. (2008). Detecting lies and deceit: Pitfalls and opportunities, second edition. Chichester: John Wiley and Sons.

Vrij, A., Fisher, R., Mann, S., \& Leal, S. (2006). Detecting deception by manipulating cognitive load. Trends in Cognitive Sciences, 10, 141-142.

Vrij, A., Fisher, R. Mann, S., \& Leal, S. (2008). A cognitive load approach to lie detection. Journal of Investigative Psychology and Offender Profiling, 5, 39-43.

Vrij, A., \& Granhag, P. A. (2012). Eliciting cues to deception and truth: What matters are the questions asked. Journal of Applied Research in Memory and Cognition, 1, 110-117.

Vrij, A., Granhag, P.A., Mann, S. \& Leal, S. (2011). Outsmarting the liars: Towards a cognitive lie detection approach. Current Directions in Psychological Science, 20, 28-32.

Vrij, A., Granhag, P. A., \& Porter, S. B. (2010). Pitfalls and opportunities in nonverbal and verbal lie detection. Psychological Science in the Public Interest, 11, 89-121.

Vrij, A., Jundi, S., Hope, L., Hillman, J., Gahr, E., Leal, S., Warmelink, L. Mann, S., Vernham, Z., \& Granhag, P. A. (2012). Collective interviewing of suspects. Journal of Applied Research in Memory and Cognition, 1, 41-44.

Vrij, A., Leal, S., Mann, S., \& Fisher, R. (2012). Imposing cognitive load to elicit cues to deceit: Inducing the reverse order technique naturally. Psychology, Crime, \& Law, 18, 579-594.

Vrij, A., Leal, S., Mann, S., Warmelink, L., Granhag, P. A., \& Fisher, R. P. (2010). Drawings as an innovative and successful lie detection tool. Applied Cognitive Psychology, 4, 587-594. DOI: $10.1002 / \mathrm{acp} / 1627$

Vrij, A., \& Mann, S. (2003). Deceptive responses and detecting deceit. In P. W. Halligan, C. Bass, \& D. Oakley (Eds.), Malingering and illness deception: Clinical and theoretical perspectives (pp. 348-362). Oxford, England: University Press.

Vrij, A., Mann, S., \& Fisher, R. (2006). Information-gathering vs accusatory interview style: 
Individual differences in respondents' experiences. Personality and Individual Differences, 41, 589-599.

Vrij, A., Mann, S., Fisher, R., Leal, S., Milne, B., \& Bull, R. (2008). Increasing cognitive load to facilitate lie detection: The benefit of recalling an event in reverse order. Law and Human Behavior, 32, 253-265.

Vrij, A., Mann, S., Jundi, S., Hope, L., \& Leal, S. (2012). Can I take your picture? Undercover interviewing to detect deception. Psychology, Public Policy, \& Law, 18, 231-244.

Vrij, A., Mann, S., Leal, S., \& Fisher, R. (2012). Is anyone out there? Drawings as a tool to detect deception in occupations interviews. Psychology, Crime, \& Law, 18, 377-388.

Walczyk, J. J., Igou, F. P., Dixon, A. P., \& Tcholakian, T. (2013). Advancing lie detection by inducing cognitive load on liars: A review of relevant theories and techniques guided by lessons from polygraph-based approaches. Frontiers in Psychology, 4, 14

Walczyk, J. J., Roper, K. S., Seemann, E., \& Humphrey, A. M. (2003). Cognitive mechanisms underlying lying to questions: Response time as a cue to deception. Applied Cognitive Psychology, 17, 755-774.

Walczyk, J. J., Schwartz, J. P., Clifton, R., Adams, B., Wei, M., \& Zha, P. (2005). Lying personto-person about live events: A cognitive framework for lie detection. Personnel Psychology, 58, 141-170.

Warmelink, L., Vrij, A., Mann, S., Jundi, S., \& Granhag, P. A. (in press). Have you been there before? The effect of experience and question expectedness on lying about intentions. Acta Psychologica.

Wegner, D. M. (1987). Transactive memory: A contemporary analysis of group mind. In B.

Mullen, \& G. Goethals (Eds.), Theories of group behavior: 185-208. New York: SpringerVerlag. 
Zimmerman, L. A., Veinott, E. S., Meissner, C. M., Fallon, C., \& Mueller, S. T. (2010). Field Training and Testing of Interview and Elicitation Methods (Final Report prepared under Contract W91CRB-09-C-0082 for US ARMY REDCOM Acquisition Center, Aberdeen Proving Ground, MD). Fairborn, OH: Klein Associates Division of Applied Research Associates.

Zuckerman, M., DePaulo, B. M., \& Rosenthal, R. (1981). Verbal and nonverbal communication of deception. In L. Berkowitz (Ed.), Advances in experimental social psychology, volume 14 (1-57). New York: Academic Press. 